\title{
Supporting volunteer mentors: Insights from a mentorship program for youth-headed households in Rwanda
}

\author{
Lisanne Brown \\ Tonya R. Thurman \\ Edward Kalisa \\ Janet C. Rice \\ Jean de Dieu Bizimana
}

See next page for additional authors

Follow this and additional works at: https://knowledgecommons.popcouncil.org/departments_sbsr-hiv

Part of the Demography, Population, and Ecology Commons, Family, Life Course, and Society

Commons, International Public Health Commons, and the Medicine and Health Commons

How does access to this work benefit you? Let us know!

\section{Recommended Citation}

Brown, Lisanne, Tonya R. Thurman, Edward Kalisa, Janet C. Rice, Jean de Dieu Bizimana, Neil W. Boris, Leslie M. Snider, and Joseph Ntaganira. 2007. "Supporting volunteer mentors: Insights from a mentorship program for youth-headed households in Rwanda," Horizons Research Summary. Washington, DC:

Population Council. 


\section{Authors}

Lisanne Brown, Tonya R. Thurman, Edward Kalisa, Janet C. Rice, Jean de Dieu Bizimana, Neil W. Boris, Leslie M. Snider, and Joseph Ntaganira 


\section{Supporting Volunteer Mentors: Insights fROM a MENTORSHIP PROgRAM FOR Youth-HEADED HouseHolds IN RwaNda}

In 2004, World Vision Rwanda (WVR), in collaboration with Tulane University and the Rwanda School of Public Health, implemented a program to provide support through regular visits by an adult mentor to youth living without adult care. The program aimed to improve psychosocial outcomes among youth by:

- Developing stable, caring relationships between youth and the adult mentors.

- Strengthening the supportive environment for children's healthy growth and development.

- Mitigating the impacts of disrupted caregiving structures and marginalization.

After completion of baseline quantitative and qualitative research, World Vision implemented the program in two areas (Karaba and Nyamagabe) of a province in southwestern Rwanda. Over an 18-month period, 156 trained adult mentors visited and supported 441 youthheaded households.

\section{Mentor Recruitment and Training}

WVR initially recruited 177 adults to be trained as volunteer mentors based on recommendations from trusted adults, community leaders, and youth in the study communities. WVR further screened these potential mentors through face-to-face interviews to assess their attitudes toward children and adolescents living in youth-headed households as well as the adults' own well-being, resulting in a total of 156 adults who were trained as mentors, of whom 60 percent were male and 40 percent were female.

\begin{abstract}
The mentor training covered key aspects of child development and skills for addressing key psychosocial issues that were identified through the baseline research. Specifically, the training addressed how to engage the youth household heads in discussion and problem solving, and how to serve as caring and interested adults. Mentors were also trained in how to interact with youth in other ways, such as playing with younger children, providing fun and recreational activities for older youth, and giving praise and encouragement. Barriers to community support and negative attitudes about orphans uncovered by the baseline research were also addressed in the training.
\end{abstract}

\section{Mentor Responsibilities}

WVR assigned each mentor two or three youth-headed households located within their own community to visit at least once every month. Mentors were responsible for monitoring the well-being of all members of the youth-headed household; providing guidance and transferring life skills; giving love, attention, and encouragement; and helping to ensure the health and safety of household members. Each visit typically lasted between one and two hours.

Using a simple pictorial monitoring form developed for the program, the mentors tracked the needs of household members, including the adequacy of available food, clothing, shelter, and the physical and emotional state of the children; the need for referrals for health care; participation and achievements in school; and

To read more about this study, go to www.popcouncil.org/horizons/projects/Rwanda_PsychOVC.htm
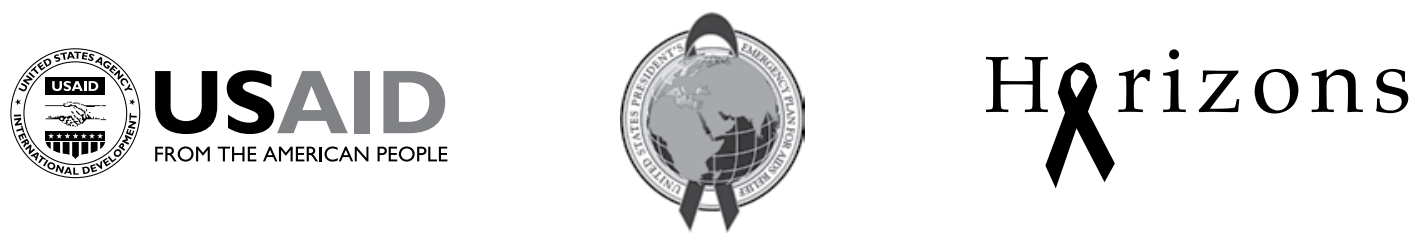
involvement in social activities. The pictorial assessments were discussed during monthly mentor meetings and submitted to WVR to help track household needs and to prioritize the distribution of WVR resources.

\section{Mentor Support}

The role of mentor is a challenging one. Mentors often reported feeling helpless in the face of the children's emotional and economic suffering and also faced a number of challenges in their own lives. WVR implemented several mechanisms to support the mentors.

- Mentors were grouped regionally into five committees of about 30 members each, providing an important forum to discuss the living conditions and struggles of the children, and to receive practical training and emotional support and encouragement from WVR, and from one another. Mentors actively participated in these monthly meetings; attendance rates were more than 90 percent throughout the study period. Refreshments and transport reimbursement for attendance at monthly meetings was provided.

- WVR worked in partnership with mentors in making key program decisions. For instance, mentors designed the program logo for the t-shirts they received, determined when the regular meetings would be held, and often developed and led the meeting agendas. In addition, when supplies to meet basic needs were limited, mentors helped determine which youth were most in need. This collaborative working relationship helped promote local ownership and direction for the program.

- Formal recognition activities were conducted, including an annual party that brought together the regional committees to showcase their work and thank them for their efforts. At the grassroots level, WVR also facilitated the recognition of mentors' work by local leaders and institutions, including church leaders who publicly acknowledged the mentorship program and volunteer efforts and allowed mentors to speak about their work at church services.

- Income-generating activities were introduced and some mentors received farming supplies.

\section{Changes Among Mentors}

Mentors participated in pre- and post-interviews that assessed the impact of the mentorship program on their psychosocial well-being. Among the 156 active mentors, 140 were interviewed at both baseline and follow up. The survey inquired about their symptoms of depression, levels of functioning, grief, and perceptions of community cohesion and available community support. The follow-up survey also included questions about the program's successes and challenges.

Mentors reported high levels of functioning at baseline, which did not change over time. All mentors indicated that the knowledge, skills, and experience they gained (e.g., problem-solving techniques, income-generating opportunities, and awareness of symptoms of psychological distress) aided them to better care for their own families.

Many mentors had experienced the loss of loved ones and, among those, grief increased significantly during the study period. This may be due to increased discussions about those who have died with the youth-headed households as well as the transference of grief as a result of helping youth cope with their own losses.

Though mentors' level of perceived community support and cohesion was high at baseline, it increased significantly over time. Mentors reported that community awareness of the voluntary work they performed coupled with the skills they acquired through training helped elevate the mentors' status in the community.

Mentors were often asked about the household visits they made and after they explained their purpose, community members praised and encouraged them to continue their important work. Mentors commented that they were perceived as "people of integrity," and were asked for advice from community members on how to handle children. A neighbor of one youth sought out a mentor specifically to comment on the positive changes observed in the children since the visits began.

Moreover, the sense of camaraderie mentors developed with one another was particularly valuable; 93 percent 
indicated that mentors help one another solve problems, and all of the mentors interviewed at follow up felt they were part of a "team."

Witnessing improvements in the lives of the children and youth, along with the joy and gratitude they extended was an important reward for the mentors. Mentors felt their work was beneficial to the lives of youth. Almost all mentors reported that youth were better protected from abuse and exploitation and were less isolated as a result of the mentor program. These observations were supported by findings from youth, who reported a decrease in marginalization and maltreatment from baseline to follow up. Mentors expressed pride in their support of vulnerable children and youth in their community and a sense of accomplishment, illustrated by the following quotes:

It makes you feel good too, because you see him happy because you solved his problem.

Mentor

We take their problems as ours, we care for them. Mentor

\section{Insights from Program Implementation}

Research results from the mentors and youth, minutes from the monthly meetings with mentors, and discussions with program staff revealed the following lessons from program implementation.

\section{Making a connection between mentors and youth may take time but can be very powerful.}

Several mentors reported that while youth were initially apprehensive and distant, after only a few visits most youth became very excited about the mentor's arrival. Overall, volunteers indicated that youth were very responsive and welcoming of the mentor. In fact, WVR staff reported that youth have traveled on their own initiative to the program office to express gratitude for the mentorship program.

Mentors also valued this relationship, as all but one indicated they considered the youth they mentored as members of their family, and 98 percent of mentors indicated they would continue to visit the households even if the formal mentor program was to stop.
Youth selection of mentors helps foster quality relationships. Youth were more receptive to mentors they nominated and mentors felt honored to be selected. The fact that youth had identified them as trusted adults provided mentors with a sense of pride and heightened their willingness and commitment to care for these youth. The process of eliciting volunteer nominations from youth also granted WVR the opportunity to sensitize youth to the role of the mentor, establish a foundation of realistic expectations, and set the stage for the development of a positive relationship.

\section{Some mentors will take independent action to address the needs of housebolds. In addition to} making home visits, several mentors acted on their own initiative to further assist youth. For instance, one youth reported to WVR that her mentor had purchased a pair of shoes for her. In another case, a mentor's persistence in reaching a "wandering" youthwho reportedly spent his days roaming the streets with friends-led to his reenrollment in school. The mentor, who is also a primary school teacher, went with the youth to register him in school and began to provide weekly tutoring sessions to help improve his scholastic performance and attitude toward education. Mentors also frequently recognized the medical needs of youth and took them to the clinic for treatment. In fact, several of the committees started a relief fund, donating a portion of their transport reimbursement each month to cover the medical expenses of youth in dire need.

\section{Ongoing motivation and capacity-building efforts are needed to empower mentors. Though} mentors engaged in independent efforts to support youth, they often felt discouraged they were unable to do more to assist them. At times, they felt powerless and overwhelmed by the extreme emotional and material needs of the youth they visited. WVR is trying to respond by offering higher-level training to select mentors to serve as counselors, as well as identifying and increasing linkages to community resources that may be able to provide additional material assistance.

WVR further recognizes the need to build the capacity of volunteers to care for themselves and their own families - both emotionally and financially. WVR is planning additional mentor-focused initiatives, such as 
expanding income-generating activities, assisting with legalizing mentor associations, and connecting mentors with additional WVR programs focusing on economic development and emotional support.

\section{Mechanisms for ensuring child and youth protection are essential. The high rates of} maltreatment reported by youth in the baseline survey (Btown et al. 2005) were instrumental in bringing the issue of child vulnerability and protection to the forefront. In response, WVR developed a list of organizations that focus on advocacy and child protection and collected details on relevant laws and processes for reporting violations. This information was incorporated into the mentor training, and mentors utilized this knowledge to assist youth in accessing legal services. WVR also worked to strengthen community capacity for child protection more broadly by providing training to local authorities on child rights and advocacy. A three-day training session was held with 42 influential community members, including church leaders, other NGO representatives operating in the area, and government authorities from the provincial, district, and sector level. In addition, WVR helped mentors establish linkages with local authorities, in order to work together to ensure protection of community youth.

WVR also ensured child protection by safeguarding the mentor and youth relationship. WVR visited each household at least twice a year without the mentor present, to allow an opportunity for the children and youth to voice any concerns and assess for possible abuse or exploitation by the mentor. Youth were encouraged to come to WVR at anytime with comments or concerns about the mentor, and were aware of their right to terminate the relationship without penalty or explanation. WVR also established Child Protection Committees facilitated by youth that provided a forum where youth can report and discuss issues pertaining to their mentor or other challenges in their lives.

\section{Negative reactions to the program need to be anticipated and countered. WVR staff} learned that it is essential to sensitize and prepare the community for the mentoring program and the direct services provided to youth-headed households. Baseline research revealed that many community members were jealous of the resources youth received from the basic needs program and needed greater understanding of the challenges facing these youth. When the mentoring component was introduced, some community members believed mentors were paid and as such, resented youth for not selecting them to be a mentor. WVR found that involvement of community members in mentor and youth beneficiary selection and sensitization campaigns to increase awareness of the issues facing orphans and vulnerable youth helped to reduce jealousy. As the program is scaledup throughout Rwanda, WVR will conduct start-up workshops at the village level to ensure that community members are aware of project activities, available resources, and constraints. It is believed that increased transparency may mitigate negative community reactions and stimulate increased interest among community members to serve as volunteer mentors. $\mathcal{X}$

\section{November 2007}

\section{Reference}

Brown, Lisanne, Tonya R. Thurman, and Leslie Snider. 2005. "Strengthening the pyschosocial well-being of youthheaded households in Rwanda: Baseline findings from an intervention trial," Horizons Research Update. Washington, D.C.: Population Council.

Suggested citation: Brown, Lisanne, Tonya R. Thurman, Edward Kalisa, Janet Rice, Jean de Dieu Bizimana, Neil Boris, Leslie Snider, and Joseph Ntaganira. 2007. "Supporting volunteer mentors: Insights from a mentorship program for youth-headed households in Rwanda," Horizons Research Summary. Washington, DC: Population Council.

\section{Hqrizons 4}

Population Council/Horizons

Communications Unit

4301 Connecticut Avenue, NW

Suite 280

Washington, DC 20008

\section{(P) Population Council}

Tel: 202-237-9400

Fax: 202-237-8410

horizons@popcouncil.org

www.popcouncil.org/horizons
This research summary is made possible by the generous support of the American people through the United States Agency for International Development (USAID) and the President's Emergency Plan for AIDS Relief under the terms of HRN-A-00-97-00012-00. The contents are the responsibility of the Horizons Program and do not necessarily reflect the views of USAID or the United States Government. 